\title{
The Use of GIS to Study the Spatial Variation of Diseases: A Case of Western Region, Ghana*
}

\author{
B. Kumi-Boateng and I. Yakubu
}

Kumi-Boateng, B. and Yakubu, I., (2009), "The Use of GIS to Study the Spatial Variation of Diseases: A Case of Western Region, Ghana”, Ghana Mining Journal, Vol. 11, pp. 1 - 6.

\begin{abstract}
The ability to formulate disease control programmes and put strategic action plans into practice has become an important issue for Regional Health Directorates in Ghana. An important factor in disease control programmes is to correlate variations in different communities with environmental factors using spatially reliable data. To achieve this, spatial distribution maps for predominant diseases such as malaria, skin infection, Respiratory Tract Infection (RTI), asthma and diarrhea for the year 2005 were created. In this study, a database of disease statistics and the geographical information representing the boundaries as well as the centre of the administrative units of the Western Region of Ghana were built using cartographic and GIS techniques - choropleth mapping to examine the spatial distribution of the selected diseases. The results show that there is a strong correlation between mining activities and the prevalence of diseases under study in the Western Region.
\end{abstract}

\section{Introduction}

Geographic Information Systems (GIS) allows spatial data handling, manipulation, and analysis with a new dimension and unparalleled flexibility. These systems provide more accurate base maps and redefine several methods of data capturing within accepted levels of accuracy. Functionality on the World Wide Web for integrating data from various sources, including photographs, video and sound data has given a new perception to spatial data management and global information sharing. Currently, GIS is finding application in diverse fields including health.

Interest in public health mapping has increased over the last decade. In fact, new disciplines devoted specifically to public health and GIS are emerging from common interests of epidemiologists, geographers and cartographers to produce meaningful maps that provide insights into the underlying processes of diseases (Stacey, 2005). In any disease control programme, there are several factors involved, such as estimation of disease burden, monitoring of disease trend, identification of risk factors, planning, allocation of resources and implementation. GIS, owing to its inherent ability to manage both spatial and non-spatial information, provides an excellent framework for disease monitoring and control.

Geomatic and public health professionals have produced a significant body of work using GIS and mapping techniques best suited for mapping and understanding of public health information. Various studies over the last 50 years focused on the practice of thematic mapping and more recently, geospatial techniques such as areal interpolation have been explored (May, 1951; Crampton, 2004; Johnson, 2004; Colak, 2005; Stacey, 2005).

Maps are defined as graphic representations that facilitate the understanding of spatial concepts, conditions, processes or events in the human world (Harley, 1989). Mapping case locations at the individual or population level is important to public health research because the spatial distributions provide insights into the environment where potential exposures of health risks may be encountered (Cromley, 2002). Public health applications of GIS are used to map the source and distribution of disease agents, identify areas where people may be exposed to environmental and biological contaminants, and analyse the spatial and temporal patterns of different health outcomes (Cromley, 2002). Linking the residential address of a newly diagnosed tuberculosis patient with demographic data provided by an appropriate statistical agency can be an effective method for identifying clusters of high incidence that can enhance targeted screening and control efforts (Moonan, 2004).

Over time disease mapping has shed light on political interests in understanding the geographic distribution of disease. Following Foucault's concept of governmentality, the relationship between public health and disease mapping are discussed in terms of power-relations and is used to explain how maps and mapping are employed to understand the geographic distribution of disease (Foucault, 2000). Using Foucault's historical analysis of government and political thought as a

* Manuscript received May 17, 2009

Revised version accepted October 2, 2009 
model, the historical analysis of disease mapping provides insight into the challenges that historically face geographers and public health researchers in order to gain perspective and provide alternative strategies for addressing modern challenges of mapping disease. This paper seeks to determine some disease density areas of the Western Region of Ghana; analyse spatially the factors contributing to the incidence rates and produce a base map for implementation by the Western Regional Health Directorate in their disease control programme.

\section{The Study Area}

Western Region covers an area of approximately $23921 \mathrm{~km}^{2}$, which is about $10 \%$ of Ghana's total land area. It is bordered on the east by the Central Region, to the west by Cote d'Ivoire, to the north by Ashanti and Brong-Ahafo Regions and to the south by the Gulf of Guinea. The Region has 11 administrative districts and a population of about 1 924 577, with a growth rate of $3.2 \%$. The population density of the region is 80.5 persons per square kilometer. It has about $75 \%$ of its vegetation within the high forest zone of Ghana; and lies in the equatorial climatic zone that is characterised by moderate temperatures with an average rainfall of $1600 \mathrm{~mm}$ per annum (Anon, 1997). The economic activities of the Region are predominantly in minerals, fishing, cocoa and timber. The Region has the highest concentration of gold mines in Ghana. It also has active bauxite and manganese mines. These industries are known (Anon, 1997) to generate considerable amounts of environmental pollutants likely to contribute to the disease patterns of the Region. Statistics available from the health directorate reveals that skin infections, malaria, diarrhoea, asthma and RTIs are the most predominant in the Region. Due to the large concentration of commercial and mining related industries, the Region attracts lots of migrant workers from the other regions of Ghana and also from the West African sub-region who may be already carrying the disease parasite (Anon, 1997).

\section{Source of Data and Organisation}

The source of data and methods employed in this paper are discussed in the following sections.

\subsection{Source of Data}

Secondary data consisting of predominant diseases in the Region for the year 2005 was obtained from the Regional Health Directorate. These were diseases recorded throughout the year 2005 for the respective Districts. The population of the region in 2005 was provided by the Ghana Statistical Department and a topographical map of the region was obtained from the Survey Department of Ghana. Data structure, descriptive statistics and disease incidence (density) rates for the various districts/administrative units were produced with $\mathrm{R}$ 2.4 software; the administrative map units and the disease distribution maps were produced using ArcGIS and ILWIS software.

\subsection{Data Organisation}

The organisation of data and methods used for the production of the base and GIS-based disease density maps are discussed in the following subsections.

\subsubsection{Disease data and base maps}

During the year 2005, the Health Directorate recorded several cases of diseases in the region. Out of these diseases, skin infection, RTI, asthma, malaria and diarrhoea were predominant and therefore were selected for this study. However, some diseases lacked adequate address information and were therefore excluded. The remaining data set were used for the production of the disease maps.

The administrative unit map of the region was used as the base map for the application to the diseases recorded. In the base map, the geographical information shows the boundaries and centre of the administrative units. The data in the map was made up of boundaries of the districts, their capitals and the communities making up the districts. An attribute map was created with the targeted population for the year 2005 using ILWIS software. The base map created was transferred into topological data structure using ArcGIS software and the data stored as shape (.shp) files. This data set comprises two data layers, one is the administrative boundaries in polygons and the other is the district capitals in points.

\subsubsection{GIS-based disease density maps}

The various cases applicable for the study were determined and the data arranged in Microsoft Excel program and stored in 'dbase' format suitable for the ArcGIS software. During this process the previously arranged geospatial data of the administrative boundaries of the region, together with district boundaries in the towns were used as the base spatial data. Each case was marked on the map with a point using its address information, generating a new disease distribution layer (Colak, 2005).

With the production of the distribution map/layer of the various diseases, the geo-spatial distribution of the cases within the region for the year 2005 were determined. However, to perform some statistical analysis and comparisons, calculation of disease incidence (density) values for each administrative unit was needed. The disease incidence rate is defined as the number of new cases of specific disease occurring in a specified population 
during a year per 100000 population at risk (Colak, 2005). For this purpose, the number of cases for each administrative boundary or unit was determined. From the data on diseases created and the targeted population in 2005 from the attribute maps, an incidence value for each unit was calculated for each disease using Equation:

Incidence Rate = (Number of New Cases)

Population) $x k$

Where $\mathrm{k}=100000$

\section{Results and Discussions}

The results of the research are discussed in sections 4.1 and 4.2 .

Table 1 : Summary Statistics of Incidence Rate of Diseases for the Year 2005

\begin{tabular}{|c|c|c|c|c|c|c|}
\hline \multirow[b]{2}{*}{ Summary } & \multicolumn{5}{|c|}{ Incidence Rate of Diseases (per 100 000) } & \multirow[b]{2}{*}{ Population } \\
\hline & Malaria & $\begin{array}{c}\text { Skin } \\
\text { Diseases }\end{array}$ & R.T.I & Asthma & Diarrhea & \\
\hline Minimum & 10408 & 893 & 2351 & 28 & 1244 & 11368 \\
\hline $\begin{array}{l}\text { 1st } \\
\text { Quartile }\end{array}$ & 20221 & 1343 & 3002 & 100 & 1748 & 134898 \\
\hline Median & 24933 & 1787 & 3433 & 130 & 1941 & 167241 \\
\hline Mean & 36848 & 2563 & 5634 & 494 & 2848 & 204805 \\
\hline $\begin{array}{l}\text { 3rd } \\
\text { Quartile }\end{array}$ & 44730 & 2625 & 5102 & 258 & 3716 & 273378 \\
\hline Maximum & 52696 & 8712 & 19063 & 3331 & 7036 & 432136 \\
\hline
\end{tabular}

(Source: Western Region Health Directorate)

\subsection{Descriptive Statistics}

To evaluate the data set, the summary statistics of recorded diseases from the 11 districts for the year 2005 and populations were evaluated. From Table 1 , skin infections range from 893 to 8712 while that of RTI ranges between 2351 and 19063 per every 100000 people at risk. The results in Table 1 also show that asthma recorded the least incidence rate of 28 people at risk per 100000 populations and malaria gave a maximum rate of 52696 .

\subsection{Spatial Distribution Map of Diseases}

Results of the spatial distribution maps of the predominant diseases are discussed in the following subsections:

\subsubsection{Malaria}

Malaria is recognised as a major case of morbidity in Ghana. Western Region recorded 405,324 cases of malaria in the year 2005. In spite of the relative efforts to control malaria over the last decades, the disease remains an important cause of morbidity in the region with a considerable number of people considered to be at high risk. An important feature of the study revealed that spatial distribution of malaria cases is not homogeneous within the region but localised depending upon the interplay between a number of factors. Thus, populations in areas that underwent extensive deforestation due to development projects (such as agricultural colonisation), or others who live in areas where mining activities take place face different risks of disease transmission. From the spatial distribution map of malaria incidence (Figure 1), it is observed that Shama, Wassa West, Nzema East, Bibiani and Juabiso Bia contributed 25.34\%, 16.37\%, 13.66\%, $8.41 \%$ and $7.98 \%$ respectively of the total cases of malaria recorded in the year 2005. It is significant to note that all the districts that recorded high incidence rate of malaria, with the exception of Shama, are mining communities. Studies conducted in Turkey, USA and Sierra Leone (ZackWilliams, 1980) reveal a significant correlation between mining and incidence of malaria. Mining operations cause extensive deforestation and environmental degradation. After an area is mined, the land is usually left exposed and degraded, making it unsuitable for farming or any other activity. If the mining is carried out on hilly areas and slopes, severe erosion takes place and flooding can result. In certain locations miners not only remove vegetation and economic trees but their activities also divert surface water drainage sources. Siltation in rivers is a common problem noticed along communities living downstream. Water collects and stagnates in the dug-out areas posing as health and safety hazards, potentially increasing the incidence of malaria and other water borne diseases. These environmental problems coupled with the migration of miners, many of whom may be already infected by the disease, lead to high incidence rates of malaria in the area. Figure 1 show that malaria risk varies widely between the mining areas and the other environmental zones defined on the basis of predominant ecologic characteristics and land use patterns. It also highlights the important role played by mining activities in triggering malaria epidemics.

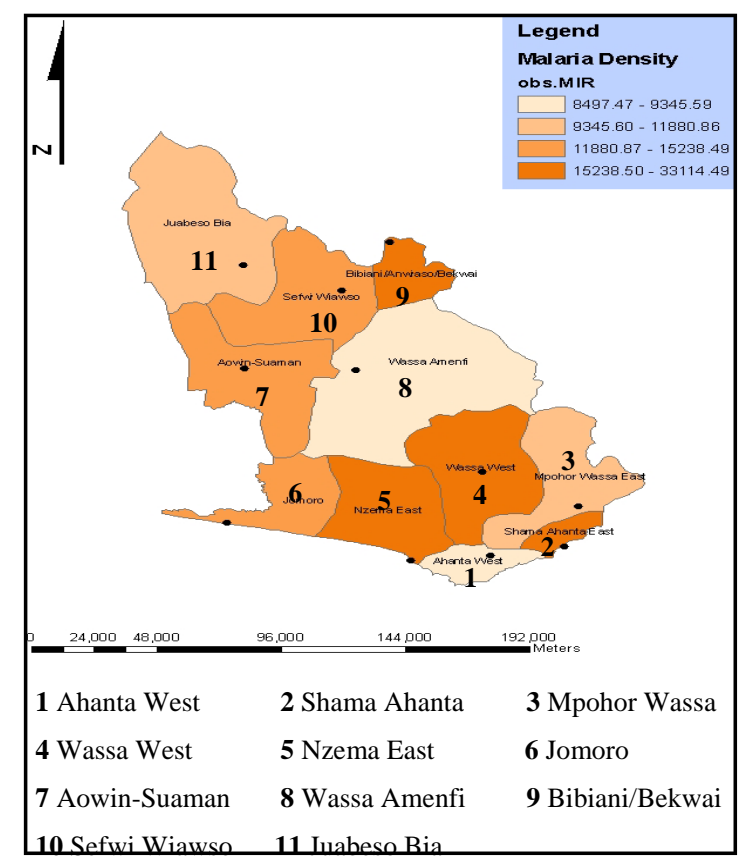

Fig. 1 Malaria Incidence Map 


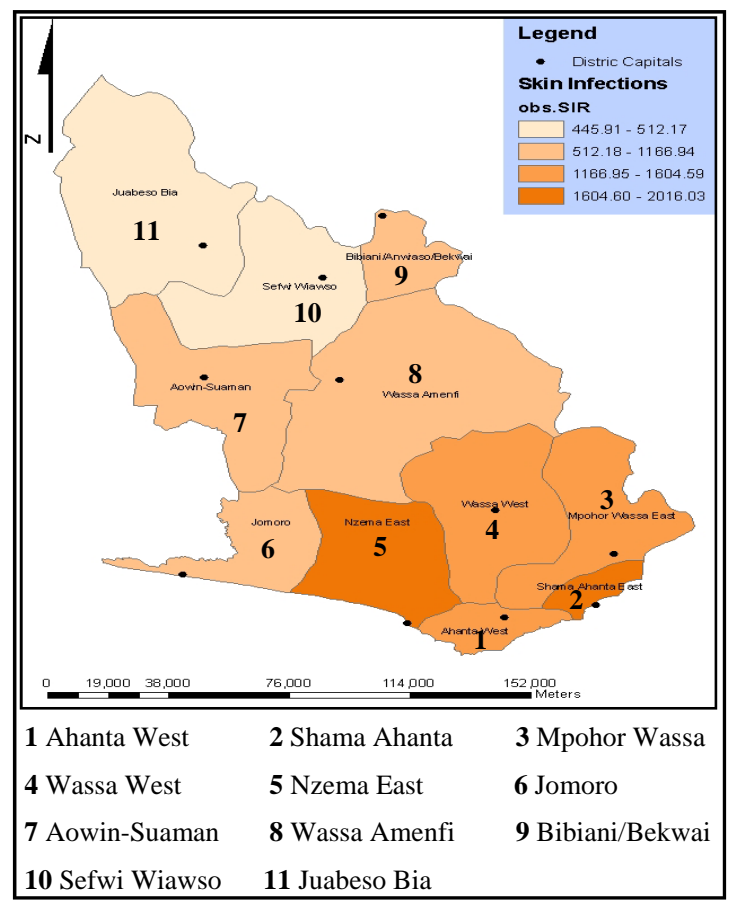

Fig. 2 Skin Infections Incidence Map

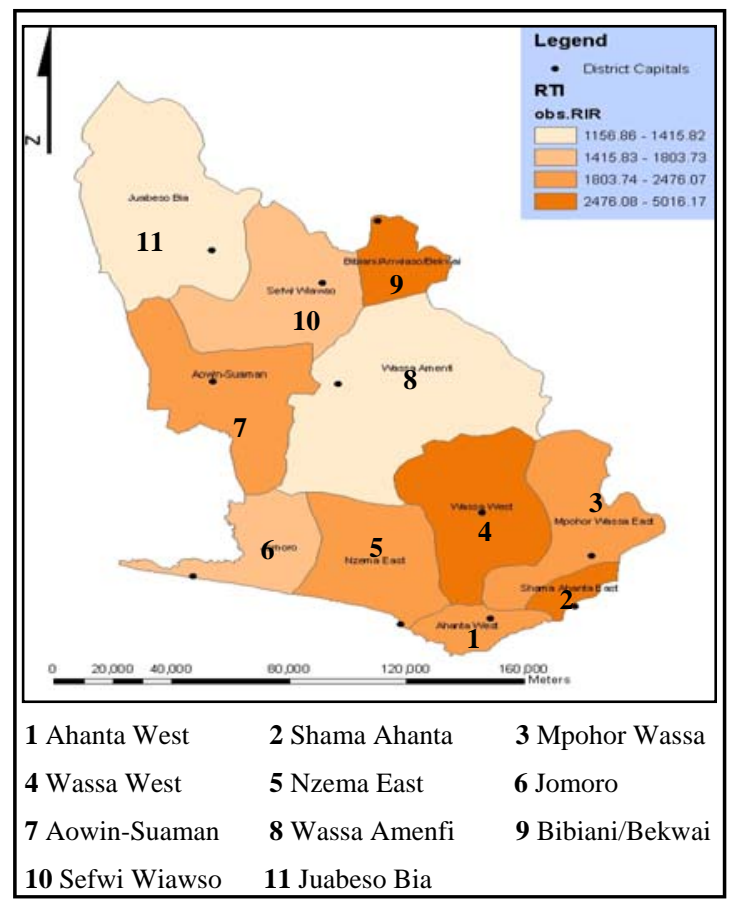

Fig. 4 Asthma Incidence Map

\subsubsection{Skin Infections}

In 2005, skin infection cases recorded were 28197 with Juabeso Bia, Nzema East and Shama Ahanta East contributing $3.34 \%, 13.26 \%$ and $15.08 \%$ per 100000 population respectively. Figure 2 revealed low incidence of cases in the northern part of the Region and high incidence of cases in the southern

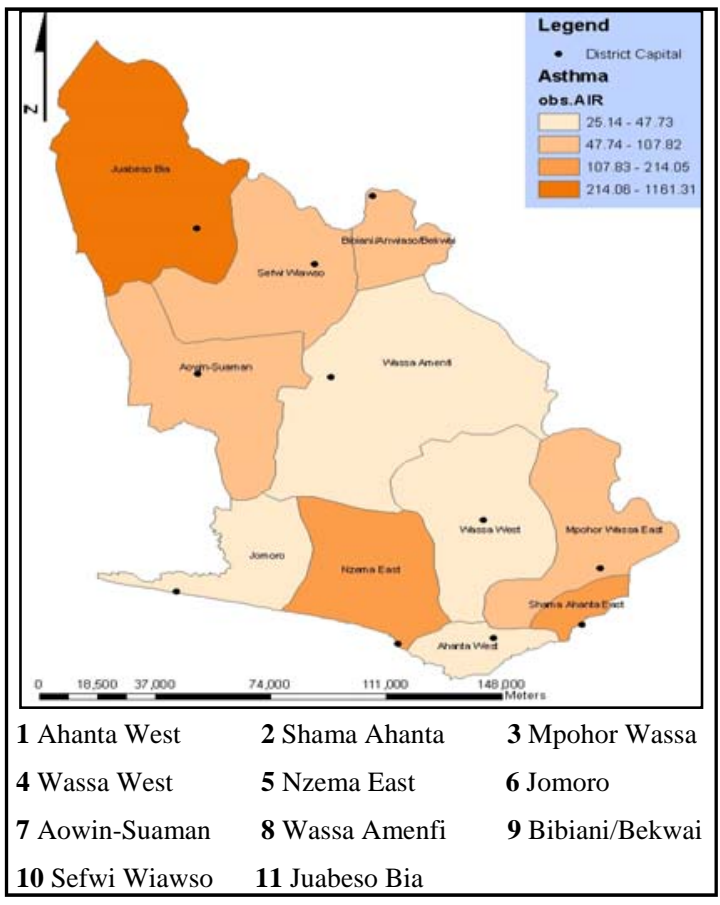

Fig. 3 RTI Incidence Map

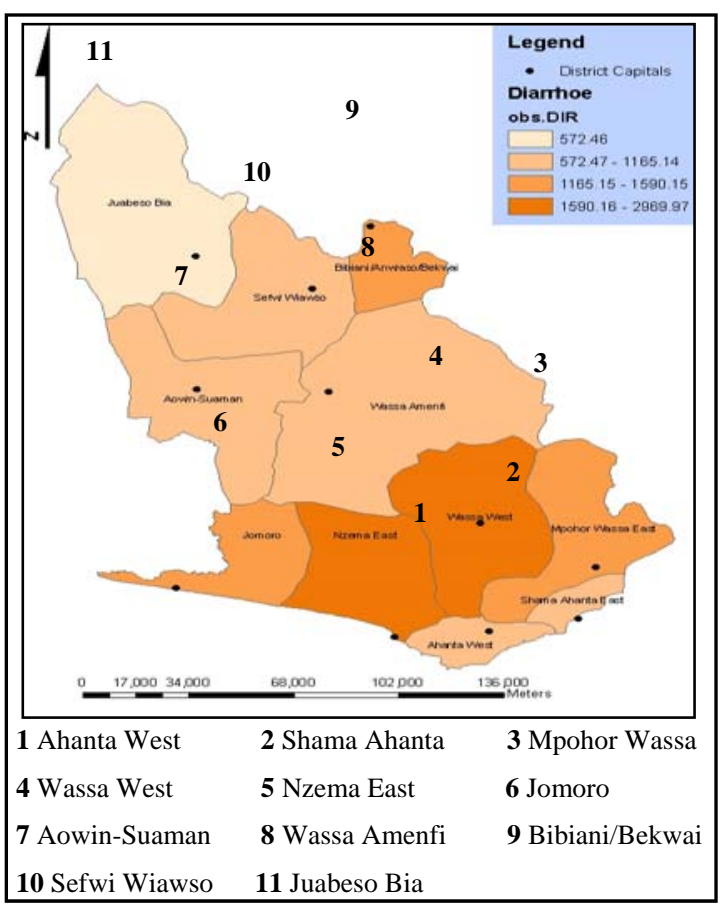

Fig. 5 Diarrhea Incidence Map

part. The high levels in the south of the region could be attributed to mining activities with concomitant release of chemicals into rivers, soils and farmlands of those districts (Alfred, 2005). Chemicals such as cyanide and mercury are used during processing of gold. Arsenic may be released by Acid Mine Drainage (AMD) and also through di- 
rect recovery processes (Kumi, 2007). These chemicals contaminate the local water sources. The contaminated water is used by the locals who may develop skin diseases and rashes due to the chemicals in the water.

\subsubsection{Respiratory Tract Infections (RTI)}

RTI is a major cause of morbidity in the Western Region. The region recorded 61971 cases of RTI in the year 2005. In spite of the efforts to control the infection over the years, it remains an important cause of morbidity in the region. As observed in the malaria distribution map (Figure 1), the spatial distribution map of RTI incidence rate is not homogenous throughout the region but localised depending upon the interplay between a number of factors such as dust emissions, cold weather etc. The road network in the Western Region is very poor. People are therefore exposed to fugitive dust (dust from tracking of vehicles) From Figure 3, it is observed that Bibiani, Wassa West and Shama Ahanta East contributed a total of $47 \%$ of the reported cases in the region. It is interesting to note that the districts with the high levels of RTI incidence rates are all mining areas with the exception of Shama Ahanta East. Shama could be experiencing the high levels due to its geographical location near to the regional capital and most referral cases are taken to the reginal capital for treatment. Various researches conducted (Anon., 2007; Anon., 2008) reveal a significant relationship between mining activities and RTI cases. Mining operations, especially surface mining generates considerable amount of dust and when inhaled by people in the neighboring communities, they may be infected.

\subsubsection{Asthma}

In the year 2005, a total of 2072 cases of asthma were recorded per every 100000 population (Figure 4). Out of this, Figure 5 shows that a total of $75 \%$ were spread within Juabeso Bia, Shama Ahanta and Nzema East districts (Figure 4). It is interesting to note that Juabeso Bia which has highest level of asthma incidence rate is a predominantly farming community. This observation contravenes the numerous studies conducted elsewhere that show that the prevalence rate of asthma in farmers is low (James, 2005; Adler, 2005; Jane, 2008). This paper reveals that not all farming environments are protected against the development of asthma as observed by Eduard (2004). The Juabeso District is located at high altitude and hence low temperatures will prevail there. It is also likely that the farmers in the District may be exposed to smoke and pollen. These conditions are ideal for asthma attack.

\section{Conclusions}

From the analysis in this paper, the following conclusions are made:

- When the incidence rates of diseases are examined spatially, it is found that disease risky districts within the Western Region have more population density than other districts.

- It can be seen from the spatial distribution maps of the diseases that areas or districts near to mining companies have more reported cases of malaria, skin infections, RTI and diarrhea.

- The mining communities within the districts contributed $74 \%, 53 \%, 47 \%$ and $44 \%$ recorded cases of malaria, skin infections, RTI and diarrhea in 2005 respectively.

- This study can be considered as a pilot application for presenting the distribution of disease incidence rate on maps to facilitate control programs against certain diseases and to examine the environmental factors causing the disease spatially.

- Finally the spatial dynamics of diseases can be shown using cartographic and GIS techniques such as choropleth mapping of disease data. However, the emerging patterns from the spatial distribution maps generated within the different districts could be developed for a period of time to provide some guidelines to the possible trend that specific diseases would take over the next five years cycle. This must, however, be met with the appropriate educational, social and clinical programs to secure some control on the spatial spread of the diseases in the Western Region.

\section{References}

Adler, A., (2005), "Decreased Prevalence of Asthma among farm-reared children”, Journal of Allergy and Clinical Immunology, pp. 1-6.

Alfred, A. D., (2005), Spatial Analysis of Factors Implicated in Mycobacterium ulcerans Infection in Ghana, ITC, Enschede, 155 pp.

Anon., (1997), Rediscovering Geography. National Research Council, National Academy Press, Washington DC, 78 pp.

Anon., (2007), Respiratory Disorders. Natural Standard Bottom Line Monograph, (www.naturalstandard.com), pp. 1-5.

Anon., (2008), Girls in Mining: Findings from Ghana, Niger, Peru and United Republic of Tanzania, International Labour Organisation, 28 pp.

Colak, E., (2005), "Creating GIS-Based Cancer 
Density Maps for Trabzon Province of Turkey", ESRI Health GIS Conference, Chicago, Illinois, USA, 2005. pp. 1-25.

Crampton, J., (2004), "GIS and Geographic Governance: Reconstructing the Choropleth Map", Cartographica, pp. 1-12.

Cromley, E. K., (2002), GIS and Public Health, The Guilford Press, New York, 28 pp.

Eduard, W., (2004), "Do Farming Exposures Cause or Prevent Asthma?: Results from a Study of Adult Norwegian Farmers", International Journal of Respiratory Medicine. pp. 15.

Foucault, M., (2000), Gonernmentality, The New York Press, $69 \mathrm{pp}$.

Harley, J., (1989), "Deconstructing the Map", Cartographica, pp. 1-20.

James, A., (2005), "Asthma and Farm Exposures in Cohort of Rural Iowa Children", Environmental Health Perspective, pp. 1-12

Jane, A., (2008), "Pesticides and Atopic and Nonatopic Asthma among Farm Women in the Agricultural Health Study", American Jounal of Respiratory and Critical Care Medicine, pp. 17.

Johnson, G. D., (2004), "Small Area Mapping of Prostate Cancer incidence in New York State (USA) using fully Bayesian Hierarchical Modelling", International Journal of Health Geographics, pp. 1-29.

Kumi, B. B., (2007), "Assessing the Spatial Distribution of Arsenic Concentration from goldmine for Environmental Management at Obuasi, Ghana", MSc Thesis, ITC Enschede , 62 pp.

May, J. M., (1951), "Map of the Distribution of Cholera", Geographical Review, pp. 1-11.

Moonan, P. B. M., (2004), "Using GIS Technology to Identify areas of Tuberculosis Transmission and Incidence", International Journal of Health Geographics, pp. 1-23.

Stacey, L. M., (2005), Cartography, Discourse and Disease: How Maps Shapes Scientific Knowledge About Disease, Geogia State University, $87 \mathrm{pp}$.

Zack-Williams, B., (1980), "Diamond mining and underdevelopement in Sierra Leone", Afrique et Developpement, Vol. 15, No. 2, pp.95-117.

\section{Authors}

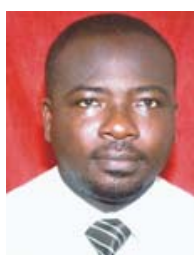

Kumi-Boateng Bernard is currently a $\mathrm{PhD}$ (Geomatic Engineering) student and a Lecturer by rank at the University of Mines and Technology (UMaT), Tarkwa-Ghana. He holds a Bachelor of Science degree in Geomatic Engineering from the Kwame Nkrumah University of Science and Technology, Kumasi-Ghana. He worked in the Department of Geomatic Engineering of UMaT as a Teaching Assistant from
2004 to 2005. He obtained his Master of Science degree from the International Institute for Geo-information Science and Earth Observation (ITC), Enschede-The Netherlands. KumiBoateng has three years University teaching experience. He has skills in the usage of Erdas, ArcGIS 9x, Definite, ILWIS, R2.4 and FCD Mapper. His research interest includes application of Remote Sensing and G.I.S in Environmental Management, Spatial Statistics, Land and Compensation Surveys.

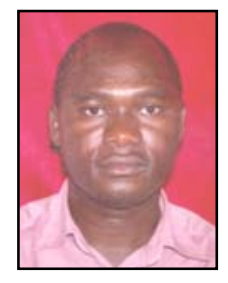

Issaka Yakubu is an Assistant Lecturer at the University of Mines and Technology (UMaT), Tarkwa-Ghana. He holds a Bachelor of Science degree in Geomatic Engineering from the Kwame Nkrumah University of Science and Technology, Kumasi-Ghana. He worked in the Department of Geomatic Engineering of UMaT as a Teaching Assistant from 2005 to 2006. He obtained his Master of Philosophy (MPhil.) degree in Geomatic Engineering from the University of Mines and Technology, Tarkwa-Ghana. He has skills in the usage of ArcGIS 9.x, ILWIS, Spectrum Survey, GNSS Solutions, SurvCAD, AutoCAD and SURPAC software. His research interest includes application of GIS, GPS and Cadastral Surveying. 